Eur. J. Clin. Chem. Clin. Biochem.

Vol. 32, 1994, pp. 759-765

(C) 1994 Walter de Gruyter \& Co.

Berlin · New York

\title{
Plasma Glutathione Peroxidase Activity as an Index of Renal Function
}

\author{
By R. Schiavon ${ }^{1}$, G. C. Guidi ${ }^{2}$, S. Biasioli ${ }^{3}$, Emanuela De Fanti ${ }^{1}$ and L. Targa ${ }^{1}$ \\ 1 Laboratorio di Analisi Chimico Cliniche e Microbiologia, Ospedale di Legnago (Verona), Italy \\ ${ }^{2}$ Laboratorio di Analisi Chimico Cliniche e Microbiologia, Centro Ospedaliero Clinicizzato, Valeggio s. M. \\ (Verona), Italy \\ 3 Servizio di Nefrologia ed Emodialisi, Ospedale di Legnago (Verona), Italy
}

(Received May 3/July 12, 1994)

Summary: The kidney is a major source of the plasma enzyme glutathione peroxidase. We measured plasma glutathione peroxidase activity in 130 patients affected with different renal diseases at various stages, and compared it with the following indices of kidney function: serum creatinine, creatinine clearance, and urinary excretion of $\alpha_{1}$-microglobulin, $\beta_{2}$-microglobulin, albumin and $\mathrm{N}$-acetyl- $\beta$ - $D$-glucosaminidase. Plasma glutathione peroxidase activity appeared significantly reduced in most of the renal diseases considered, and showed a significant correlation with most of the renal function indices. Linear discriminant analysis showed that the set of indices composed of plasma glutathione peroxidase activity, serum creatinine and creatinine clearance allowed the best classification of renal diseases. During treatment with the nephrotoxic aminoglycoside, tobramycin, plasma glutathione peroxidase activity showed an early and progressive decrease. We suggest the measurement of plasma glutathione peroxidase activity as an adjunctive index for the assessment of kidney alterations.

\section{Introduction}

In order to assess renal function, a series of laboratory tests that investigate different mechanisms of renal physiology has been proposed. An exhaustive review concerning this topic has been recently published (1).

The purpose of these laboratory measurements is mainly to improve the accuracy of the diagnostic process, thereby reducing the necessity for more invasive procedures such as kidney biopsy. At present, glomerular filtration, urine protein excretion, water. and electrolyte metabolism disturbances are investigated, using appropriate laboratory tests. Most of the commonest tests are actually both dependent on, and influenced by, the excretory status of the kidney. In this respect glomerular filtration as assessed by creatinine clearance may be biased by tubular mechanisms of excretion, thus reducing the usefulness of this measurement (2); on the other hand the ascertainment of tubular function from the excretion of specific urine proteins, such as microglobulins, may be influenced by their actual protein load on the proximal tubular cells, thus limiting the specificity of such markers (3). In this study we present evidence that a plasma enzyme known as glutathione peroxidase ${ }^{1}$ ) can be used in assessing kidney damage independently from other known indices. Plasma glutathione peroxidase is a selenium-dependent enzyme expressed in human kidney and in some other tissues $(4,5)$. Glutathione peroxidase activity is reported to be markedly depressed in chronic renal failure and in dialysed individuals regardless of the selenium status (6), which contradicts reports on its relationship to the alimentary selenium supply in healthy individuals (7). Nevertheless, this index has not yet been evaluated in comparison with other established tests of renal function, and it has not yet been used for the diagnosis of different kidney diseases. In the present paper we discuss the results obtained after measuring plasma glutathione peroxidase together with

\footnotetext{
1.) Enzymes:

Glutathione peroxidase (GSH : $\mathrm{H}_{2} \mathrm{O}_{2}$ oxidoreductase, EC 1.11.1.9)

$\mathrm{N}$-acetyl- $\beta$ - $D$-glucosaminidase (EC 3.2.1.29)
} 
tests devised to explore either the glomerular filtration rate or the damages to the glomerular and proximal tubular sites of the nephron. We confirm preliminary data (8) and show that plasma glutathione peroxidase can be a suitable index for the differential evaluation of kidney diseases.

\section{Materials and Methods}

\section{Patients}

One hundred and thirty individuals aged 13-91 years (58.6 \pm 18.0 , mean $\pm S D$ ), affected with different types of renal diseases, were studied. Patients were subdivided into seven groups according to their diagnosis (tab. 1).

\section{Samples}

Serum and EDTA plasma were obtained from blood withdrawn from fasting individuals in the early morning.

Urine samples were from 24-hour collections and from random specimens. $: i$

\section{Plasma glutathione peroxidase activity}

Measurements were performed at $37^{\circ} \mathrm{C}$ and at $340 \mathrm{~nm}$ on plasma using an automated adaptation of the method proposed by Günzler et al. (9) on an RA-1000 autoanalyser (Bayer). Briefly, tert-butylhydroperoxide $0.12 \mathrm{mmol} / \mathrm{l}$ was used as starter in a $\mathrm{pH} 7.4,0.1$ $\mathrm{mol} / \mathrm{l}$ phosphate buffered system containing the following reagents: $20 \mathrm{mmol} / 1 \mathrm{Na}_{2}$ EDTA, $0.2 \mathrm{mmol} / 1 \mathrm{NADPH}, 1 \mathrm{mmol} / \mathrm{l}$ reduced glutathione, $1.25 \mathrm{U} / 1$ glutathione reductase (final concentrations); plasma was added at a ratio of 1/50 with respect to the final volume. Catalytic activity concentration was expressed as U/l, corresponding to $\mu$ moles of NADPH oxidized per minute and litre.

Tab. 1 Groups of patients according to their diagnosis.

\begin{tabular}{|c|c|c|c|c|}
\hline Group & $\begin{array}{l}\text { Number of } \\
\text { patients }\end{array}$ & $\hat{\sigma}$ & q & $\begin{array}{l}\text { Age } \\
\text { (a) }\end{array}$ \\
\hline Glomerulonephritis & 19 & 12 & 7 & $14-68$ \\
\hline $\begin{array}{l}\text { Hereditary tubular } \\
\text { disorders }\end{array}$ & $\begin{array}{c}7 \text { (renal } \\
\text { glycosuria) } \\
7 \text { (Bartter's } \\
\text { syndrome) }\end{array}$ & $\begin{array}{l}7 \\
4\end{array}$ & $\begin{array}{l}0 \\
3\end{array}$ & $\begin{array}{l}13-83 \\
20-85\end{array}$ \\
\hline $\begin{array}{l}\text { Tubulointerstitial } \\
\text { diseases due to } \\
\text { aminoglycosides }\end{array}$ & 63 & 42 & 21 & $26-91$ \\
\hline $\begin{array}{l}\text { Chronic renal } \\
\text { failure not } \\
\text { undergoing } \\
\text { dialysis }\end{array}$ & 20 & 14 & 6 & $35-80$ \\
\hline $\begin{array}{l}\text { Prerenal azotaemia } \\
\text { due to congestive } \\
\text { heart failure }\end{array}$ & 6 & 2 & 4 & $33-76$ \\
\hline $\begin{array}{l}\text { Renal transplantation } \\
\text { recipients }\end{array}$ & 8 & 7 & 1 & $28-49$ \\
\hline Controls & 20 & 10 & 10 & $16-57$ \\
\hline
\end{tabular}

\section{Creatinine clearance}

Serum and urine creatinine was measured using an automated kinetic Jaffe method (10). Clearance was expressed as $\mathrm{ml} / \mathrm{min}$ and normalized to the body surface area $\left(1.73 \mathrm{~m}^{2}\right)$.

\section{Urinary proteins}

$: \mathbf{1}$

$\alpha_{1}$-Microglobulin, $\beta_{2}$-microglobulin and albumin were measured on fresh random samples by immunonephelometry on Behring Nephelometer Systems (Behring, Scoppito-L'Aquila, Italy), using commercial polyclonal antiserum and calibrators (Behring for either $\alpha_{1}$-microglobulin or albumin, and Biosys Diagnostici, Varedo-Milan, Italy, for $\beta_{2}$-microglobulin) (11-13).

$\mathrm{N}$-acetyl- $\beta-D$-glucosaminidase ${ }^{\mathrm{I}}$ ) was assayed on a Hitachi 704 analyser using a commercial kit (Boehringer Mannheim, Germany) (14).

\section{Analytical and biological variability of plasma} glutathione peroxidase

Within run analytical variability was measured on pooled normal plasma by thirty consecutive replicates; between days analytical variability was similarly estimated by assays conducted on the same pooled plasma during thirty consecutive days. Biological variability was calculated on six healthy individuals, three males and three females, aged 22-44. Blood samples were withdrawn at weekly intervals for the period of one month.

\section{Aminoglycoside treatment}

Two elderly female patients, aged 88 (case 1) and 99 (case 2) affected with bronchoalveolar infectious disease, were treated with i. m. tobramycin, $200 \mathrm{mg} /$ day for 7 days. Plasma glutathione peroxidase activity, serum creatinine, urinary excretion of albumin and $\alpha_{1}$-microglobulin were monitored daily before the administration of the first dose (day 1), then subsequently until day 8 .

\section{Statistical methods}

Results of the disease groups were compared with the aid of the Wilcoxon rank-sum test for unpaired data, and reciprocal correlations were calculated by linear regression analysis. Linear dis criminant analysis, a multivariate method, was used to identify the set of laboratory tests more suitable for the classification of the kidney diseases.

\section{Results}

\section{Renal function indices}

Data of the indices of renal function in the chosen kidney diseases are reported in table 2. Plasma glutathione peroxidase activity appeared to be significantly reduced in the following diseases: Bartter's syndrome, chronic renal failure, prerenal azotaemia $(p<0.001)$ and in renal transplants $(p<0.05)$. Creatinine clearance was significantly decreased $(p<0.001)$ in all but the renal glycosuria group; serum creatinine levels were significantly

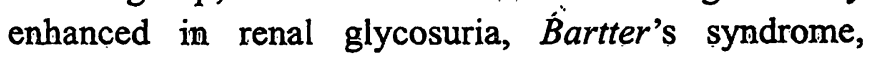
chronic renal failure, renal transplants $(p<0.001)$ and in the glomerulonephritis and prerenal azotaemia groups $(p<0.05)$; urinary $\alpha_{1}$-microglobulin excretion was significantly increased $(p<0.001)$ in all the groups, except 
T'ab. 2 Data (mean; in parentheses: SEM) collected from different groups of patients with renal discuse.

\begin{tabular}{|c|c|c|c|c|c|c|c|}
\hline \multirow[t]{2}{*}{ Group } & \multirow{2}{*}{$\begin{array}{l}\text { Scrum } \\
\text { creatinine }\end{array}$} & \multirow{2}{*}{$\begin{array}{l}\text { Creatininc } \\
\text { clcarance }\end{array}$} & \multirow{2}{*}{$\begin{array}{l}\begin{array}{l}\text { Plasma } \\
\text { glutathions } \\
\text { peroxidase }\end{array} \\
\text { U/1 }\end{array}$} & \multirow{2}{*}{$\begin{array}{l}\text { Urine } \\
\alpha_{1} \text { micro- } \\
\text { globulin } \\
\mathrm{g} / \mathrm{mol} \\
\text { creatinine }\end{array}$} & \multirow{2}{*}{$\begin{array}{l}\text { Urinc } \\
N \text {-acetyl- } \\
\beta \text { - } D \text {-glucos- } \\
\text { aminidasc } \\
U / I\end{array}$} & $\begin{array}{l}\text { Urine } \\
\beta_{2-1 \text { inicro- }} \\
\text { globulin }\end{array}$ & $\begin{array}{l}\text { Urine } \\
\text { albumin }\end{array}$ \\
\hline & & & & & & $\begin{array}{l}\mathrm{mg} / \mathrm{mol} \\
\text { creatinine }\end{array}$ & $\begin{array}{l}\mathrm{g} / \mathrm{mol} \\
\text { creatinine }\end{array}$ \\
\hline Glomerulonephritis & $132(12)$ & $89.9(10.9)$ & $138.7(11.5)$ & $2.16(0.37)$ & $6.4(1.3)$ & $85.8 \quad(45.9)$ & $22.9(11.9)$ \\
\hline Renal glycosuria & $87 \quad(8)$ & $123.3(15.9)$ & $182.2(12.2)$ & $0.67(0.11)$ & $7.5(5.5)$ & $(2.8)$ & $6.6 \quad(0.5)$ \\
\hline Bartter's syndrome & $263(64)$ & $38.7(13.0)$ & $85.7 \quad(8.7)$ & $12.6(5.3)$ & $2.3(0.7)$ & $2814 \quad(1257)$ & $45.7(37.0)$ \\
\hline $\begin{array}{l}\text { Tubulointerstitial } \\
\text { discase due to } \\
\text { aninoglycosides }\end{array}$ & $98(7)$ & $62.7(4.7)$ & $141.6 \quad(6.1)$ & $16.2(2.9)$ & $14.6(2.2)$ & $(410)$ & $15.7 \quad(6.2)$ \\
\hline $\begin{array}{l}\text { Chronic renal } \\
\text { failure not } \\
\text { undergoing dialysis }\end{array}$ & $478(46)$ & $15.0(2.6)$ & $84.8 \quad(5.2)$ & $30.4(5.0)$ & $10.3(2.1)$ & $(952)$ & $33.1(13.3)$ \\
\hline Prerenal azotacmia & $219(52)$ & $32.8(11.9)$ & $87.7(18.6)$ & $9.3(3.2)$ & $8.4(2.8)$ & $4281 \quad(17(02)$ & $15.5 \quad(6.4)$ \\
\hline $\begin{array}{l}\text { Renal } \\
\text { transplantation } \\
\text { recipients }\end{array}$ & $162(34)$ & $70.8(10.2)$ & $120.9(9.1)$ & $2.9(1.4)$ & - & - & 16.4 \\
\hline Controls & $88 \quad(3)$ & $122.7(4.7)$ & 140.0 & $0.56(0.09)$ & $1.8(0.1)$ & $(1.4)$ & $1.0 \quad(0.3)$ \\
\hline
\end{tabular}

the renal glycosuria and renal transplants groups; urinary $\beta_{2}$-microglobulin excretion was increased in Burller's syndrome, tubulointerstitial disease from aminoglycosides, chronic renal failure $(p<0.001)$, in prerenal azotaemia $(p<0.01)$ and in the glomerulonephritis and renal glycosuria groups $(p<0.05)$ (renal transplant group not evaluated); urinary $\mathrm{N}$-acetyl- $\beta$ - $D$-glucosaminidase activity was significantly enhanced in glomerulonephritis, tubulointerstitial disease from aminoglycosides, chronic renal failure $(p<0.001)$ and in the prerenal azotaemia groups $(p<0.05)$ (renal transplant group not evluated); finally, urinary albumin excretion was significantly increased in tubulointerstitial disease from aminoglycosides, chronic renal failure, renal transplants $(p<0.001)$ and in the prerenal azotaemia $(p<0.01)$ groups.

Plasma glutathione peroxidase activity showed a good correlation with serum creatinine $(r=-0.61$, $p<0.001)$, creatinine clearance $(r=0.56, p<0.001)$, $\alpha_{1}$-microglobulin $(r=-0.43, p<0.001)$ and, to a minor extent, with $\beta_{2}$-microglobulin $(r=-0.28, p<0.01)$ and albumin $(r=-0.19, p<0.05)$ urinary excretion (fig. 1).

\section{Linear discriminant analysis}

Linear discriminant analysis showed that the set of measurements consisting of plasma glutathione peroxidase activity, creatinine clearance and serum creatinine al- lowed the best classification of Bartter's syndrome and chronic renal failure groups $(43 \%$ and $85 \%$ respectivcly). Moreover, this set of analyses failed to classify the prerenal azotaemia group ( $0 \%)$. In other sets of indices, the control group was correctly classified only when plasma glutathione peroxidase was included (the best classification being $80 \%$, the worst one $35 \%$, with and without the inclusion of plasma glutathione peroxidase, respectivcly).

Plasma glutathione peroxidase analytical and biological variability

Within run and between days and analytical variability $\left(\mathrm{CV}_{\mathrm{a}} \%\right)$ were 2.16 and 4.02 , respectively. Mean biological variability $\left(\mathrm{CV}_{\mathrm{i}} \%\right)$ in a group of six healthy individuals was 6.02 .

\section{Aminoglycoside treatment}

Figure 2 shows the daily data for plasma glutathione peroxidase activity, serum creatinine levels, and $\alpha_{1}$ microglobulin and albumin urinary excretion in two patients during one weck of treatment with tobramycin.

Case 1 (fig. 2a) exhibited a marked decrease of glutathione peroxidase activity as early as day 2 , although serum creatinine levels were in the lower range of the reference values. Urinary albumin excretion, already el- 

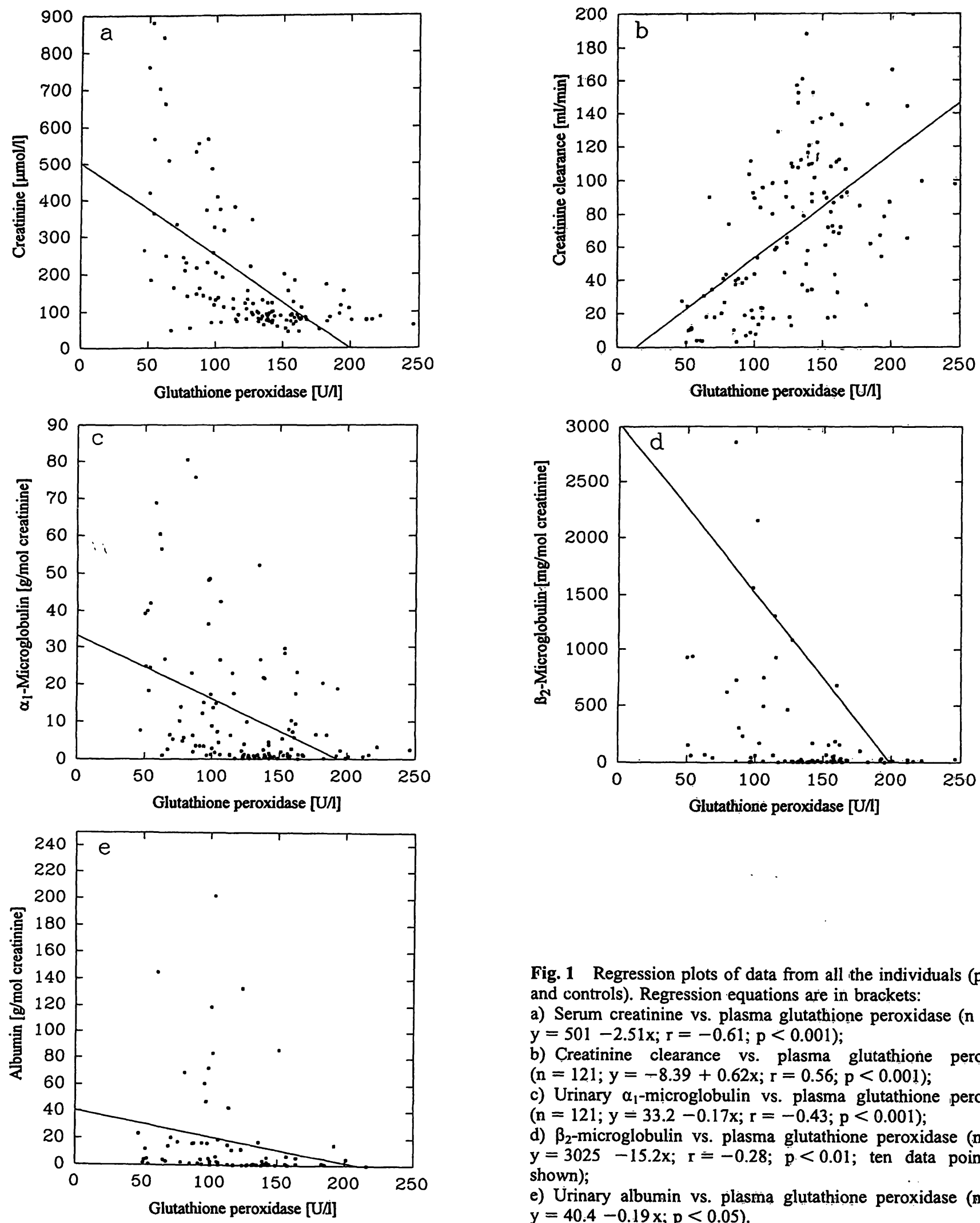

Fig. 1 Regression plots of data from all the individuals (patients and controls). Regression equations are in brackets:

a) Serum creatinine vs. plasma glutathione peroxidase $(n=121$; $\mathrm{y}=501-2.51 \mathrm{x} ; \mathrm{r}=-0.61 ; \mathrm{p}<0.001)$;

b) Creatinine clearance vs. plasma glutathione peroxidase $(\mathrm{n}=121 ; \mathrm{y}=-8.39+0.62 \mathrm{x} ; \mathrm{r}=0.56 ; \mathrm{p}<0.001)$;

c) Urinary $\alpha_{1}$-microglobulin vs. plasma glutathione peroxidase $(\mathrm{n}=121 ; \mathrm{y}=33.2-0.17 \mathrm{x} ; \mathrm{r}=-0.43 ; \mathrm{p}<0.001$ );

d) $\beta_{2}$-microglobulin vs. plasma glutathione peroxidase $(n=88$; $\mathrm{y}=3025-15.2 \mathrm{x} ; \mathrm{r}=-0.28 ; \mathrm{p}<0.01 ;$ ten data points not shown);

e) Ürinary albumin vs. plasma glutathione peroxidase $(n=78$; $y=40.4-0.19 x ; p<0.05$ ).

evated at the start of the treatment (day 1), markedly increased only after three days of treatment (day 4). In case 2 (fig. $2 b$ ), the starting value of plasma glutathione peroxidase was already low $(95 \mathrm{U} / \mathrm{l})$ and the value of albuminuria was above the upper normal reference range $(4.06 \mathrm{~g} / \mathrm{mol}$ creatinine). On day 5 , while serum creatinine values were still within the normal reference range, plasma glutathione peroxidase activity showed a further decrease. In any case, although no marked alterations of glomerular filtration rate were found, it was noticed that plasma glutathione peroxidase activity tended to decrease concomitant with an increase of serum creatinine levels. Enhanced urinary albumin excretion was an early sign of the effect of the idrug on the kidney. 


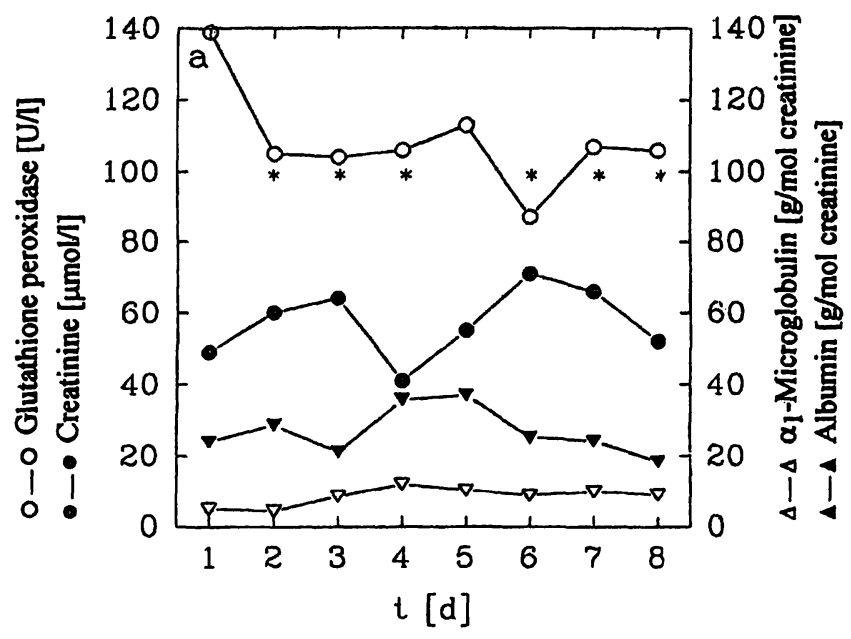

Fig. 2 Effects of aminoglycoside (tobramycin) treatment on renal function tests. Graph a refers to case 1, which shows a more pronounced decrease of plasma glutathione peroxidase activity, while graph b represents a milder condition (case 2); plasma glutathione

\section{Discussion}

The activity of the enzyme, plasma glutathione peroxidase, was significantly reduced in chronic renal failure $(p<0.001)$ and in some of the kidney diseases studied, namely Bartter's syndrome, prerenal azotaemia $(p<0.001)$ and also in renal transplants $(p<0.05)$, irrespective of the serum creatinine levels. A number of enzyme activities has been proposed for evaluating renal tubular damage, including $\mathrm{N}$-acetyl- $\beta-D$-glucosaminidase, $\gamma$-glutamyltransferase, ribonuclease (15) and glutathione-S-transferase (16). However, these have to be measured in urine samples, since they are excreted in cases of proximal tubular damage, involving either brush border or lysosomes. In contrast, plasma glutathione peroxidase activity is assayed in plasma and seems to reflect the amount of the enzyme synthesized by the kidney. The functional role of plasma glutathione peroxidase has not been fully elucidated, although it is thought to have a protective function against lipoprotein peroxidation, mainly by reducing phosphatidylcholine hydroperoxide (17). Also, a local mechanism against renal glomerular.injury by free radicals has been attributed to plasma glutathione peroxidase, similar to that of other scavenger molecules (18-19). We previously demonstrated that by increasing the oral intake.of Se, a known trace element essential for plasma glutathione peroxidase synthesis, the glomerular filtration rate could be stably improved (20). Low plasma glutathione peroxidase activities have been found in chronic renal failure patients and this could account for the accelerated atherosclerotic process peculiar to these individuals (21). The kidney is in fact the most important site of synthesis of plasma glutathione peroxidase (4) and the metabolism of reduced glutathione is very active in this organ (22). Therefore, the measurement of plasma gluta-

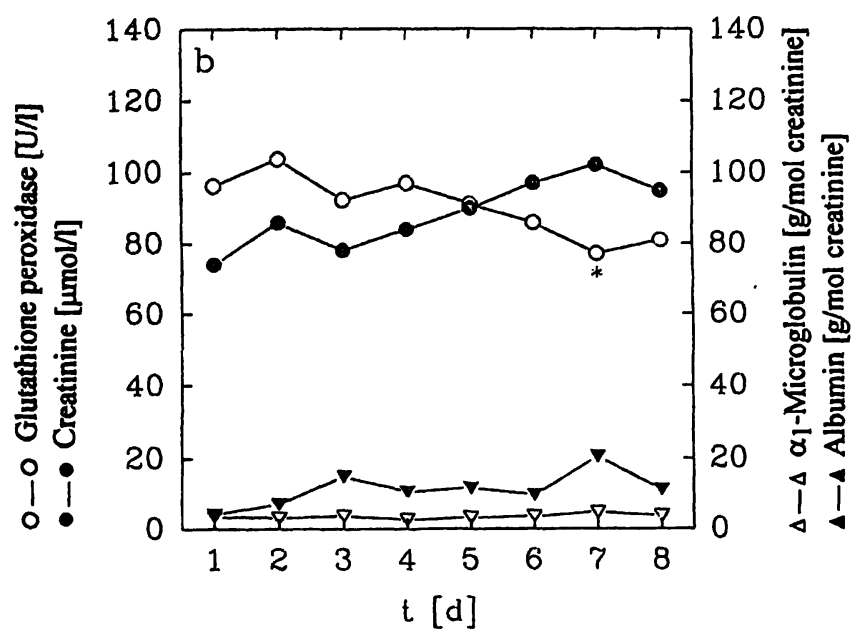

peroxidase $\mathrm{U} / 1 \mathrm{O}$; serum creatinine $\mu \mathrm{mol} / \mathrm{l} \boldsymbol{\bullet}$; urinary $\alpha_{1}$-microglobulin $\mathrm{g} / \mathrm{mol}$ creatinine $\nabla$; urinary albumin $\mathrm{g} / \mathrm{mol}$ creatinine $\nabla$. Asterisks mark significant differences for plasma glutathione peroxidase.

thione peroxidase activity can be expected to be a sensitive index of kidney function, unaffected by the preanalytical errors of urine collection. Actually, plasma glutathione peroxidase activity was significantly correlated with the most effective laboratory indices of kidney function, namely serum creatinine, creatinine clearance, $\alpha_{1}$-microglobulin, $\beta_{2}$-microglobulin and albumin urinary excretion (fig. 1). Although the plasma glutathione peroxidase gene seems to be expressed in other human tissues besides the kidney (5), the association of low enzyme activity in the plasma of patients with some kidney disorders, along with other laboratory indicators of renal function, suggests that the kidney is a main determinant of the levels of plasma glutathione peroxidase. We used a multivariate statistical method (linear discriminant analysis) to evaluate the contribution made by plasma glutathione peroxidase data to a set of related measurements of renal function commonly performed. When individuals belonging to previously defined kidney diseases were again classified using the discriminant function obtained by the above mentioned statistical procedure, the following conclusions could be drawn:

1) the set composed of plasma glutathione peroxidase plus creatinine clearance and serum creatinine allowed the most correct classification of Bartter's syndrome and chronic renal failure, compared with all other sets of laboratory variables;

2) the same set was unable to classify the prerenal azotaemia group: this fact appears to reinforce the conclusion that plasma glutathione peroxidase contributes to the classification of primary kidney damage;

3) $\alpha_{1}$-microglobulin and, above all, $\beta_{2}$-microglobulin excretion did not increase the correctness of the classifi- 
cation when plasma glutathione peroxidase was not considered in the statistical procedure.

Therefore, in order to discriminate more extensively between kidney diseases, we suggest that the measurement of plasma glutathione peroxidase activity should be complemented by the determination of serum creatinine and creatinine clearance. However, we emphasize that in observing the excretion patterns, the natural progression of the disease must be considered; in fact, atrophy and degeneration, as well as regeneration and recovery of proximal tubules and loss of glomerular barrier function of damaged kidneys, may occur simultaneously (23). Moreover, as plasma glutathione peroxidase seems to be directly synthesised by the nephron, its activity might be representative of the residual functional mass of the kidney, unaffected by mechanisms of either filtration or excretion. Alternatively, the perfusion of the kidney may determine glutathione peroxidase plasma levels; the latter being significantly increased in renal glycosuria, but decreased in the renal diseases mentioned above. We therefore maintain that plasma glutathione peroxidase should be considered a unique index of renal function, different from all laboratory quantities.

\section{References}

1. Cohen, E. P. \& Lemann, J. Jr. (1991) The role of the laboratory in the evaluation of kidney function. Clin. Chem. 37, 785796.

2. Shemesh, O., Golbetz, H., Kriss, J. P. \& Myers, B. D. (1985) Limitation of creatinine as a filtration marker in glomerulopathic patients. Kidney Int. 28, 830-838.

3. Lapsley, M., Sansom, P. A., Marlow, C. T., Flynn, F. V. \& Norden, A. G. W. (1991) Beta2-glycoprotein-1 (apolipoprotein $\mathrm{H})$ excretion in chronic renal tubular disorders: Comparison with other protein markers of tubular malfunction. J. Clin. Pathol. 44, 812-816.

4. Yoshimura, S., Suemizu, H., Taniguchi, Y., Watanabe, K., Nomoto, Y., Katsuoka, Y., Arimori, S. \& Moriuchi, T. (1991) Molecular cloning of human plasma glutathione peroxidase gene and its expression in the kidney. Nucleic Acids Symp. Ser. 25, 163-164.

5. Chu, F-F., Esworthy, R. S., Doroshow, J. H., Doan, K. \& Liu, $X-F$. (1992) Expression of plasma glutathione peroxidase in human liver in addition to kidney, heart, lung and breast in humans and rodents. Blood 79, 3233-3238.

6. Richard, M. J., Arnaud, J., Jurkovitz, C., Hachache, T., Meftahi, H., Laporte, F., Foret, M., Favier, A. \& Cordonnier, D. (1991) Trace elements and lipid peroxidation abnormalities in patients with chronic renal failure. Nephron 57, 10-15.

7. Cohen, H. J., Chovaniek, M. E., Mistretta, D. \& Baker, S. S. (1985) Selenium repletion and glutathione peroxidase-differential effects on plasma and red blood cell enzyme activity. Am. J. Clin. Nutr. 41, 735-747.

8. Schiavon, R., De Fanti, E., Targa, L., Biasioli, S., Cirillo, F. M., Andrei, O. \& Guidi, G. C. (1993) Plasma glutathione peroxidase activity (GSHPx-P) as a peculiar index of renal function. (Abstr.) Ann. Biol. Clin. 51, 429.

9. Günzler, W. A., Kremers, H. \& Flohè, L. (1974) An improved ${ }^{\circ}$ coupled test procedure for glutathione peroxidase (EC
The narrow biological variability shown by plasma glutathione peroxidase activity means that this enzyme activity is a suitable quantity for monitoring changes in kidney function (24). In fact, plasma glutathione peroxidase activity did progessively decrease during the aminoglycoside treatment, $a_{i}$ type of drug known to cause a renal functional derangement in up to 36 percent of patients, predominantly restricted to the proximal tubule, where the aminoglycosides accumulate (25). Indeed, differences between two successive results greater than the critical difference were registered on several occasions (fig. 2). This observation gives further biological plausibility to plasma glutathione peroxidase as an index of renal function assessment. Moreover, the decrease of plasma glutathione peroxidase activity during aminoglycoside treatment preceded the increase of serum creatinine; this is similar to the excretion of urinary $\beta_{2}$-microglobulin, which preceded the decrease in glomerular filtration rate (26). In conclusion we consider the measurement of plasma glutathione peroxidase activity to be a new and important adjunct in the diagnosis of renal diseases, especially when more information is needed on tubular-interstitial alterations. Further investigations should be encouraged in this field.

1.11.1.9) in blood. Z. Klin. Chem. Klin. Biochem. 12, 444448.

10. Larsen, K. (1972) Creatinine assay by a reaction-kinetic principle. Clin. Chim. Acta 41, 209-217.

11. Dati, F., Lammers, M., Kapmeyer, W. H., Weber, M. H. \& Zoppi, F. (1991) Immunonephelometric assay of alphal =microglobulin in urine. Clin. Chem. 37, 1064.

12. Iguaz, F., Naval, J. \& Borque, L. (1992) Measurement of serum beta 2-microglobulin by a latex nephelometric immunoassay. Clin. Biochem. 25, 245-249.

13. Marre, M., Claudel, J-P., Ciret, P., Luis, N., Suarez, L. \& Passa P. (1987) Laser immunonephelometry for for routine quantification of urinary albumin excretion. Clin. Chem. 33, 209213.

14. Noto, A., Ogawa, Y., Mori, S., Yoshiko, M., Kitakaze, T., Hori, T., Nakamura, M. \& Miyake, T. (1983) Simple rapid spectrophotometry of urinary $\mathrm{N}$-acetyl-beta-D-glucosaminidase with use of a new chromogenic substrate. Clin. Chem. 29, 17131716.

15. Jung, K., Shulze, B-D. \& Sydow, K. (1987) Diagnostic significance of different urinary enżymes in patients suffering from chronic renal diseases. Clin. Chim. Acta 168, 285-295.

16. Backman, L., Appelkvist, E-L., Ringden, O. \& Dallner, G. (1988) Glutathione transferase in the urine: A marker for posttransplant tubular lesions. Kidney Int. 33, 571-577.

17. Yamamoto, Y., Nagata, Y., Niki, E., Watanabe, K. \& Yoshimura, S. (1993) Plasma glutathione peroxidase reduces phosphatidylcholine hydroperoxide. Biochem. Biophys. Res. Comm. 193, 133-138.

18. Tay, M., Comper, W. D., Vassiliou, P., Glasgow, E. F., Baker, M. S. \& Pratt, L. (1990) The inhibitory action of oxygen radical scavengers on proteinuria and glomerular heparan sulphate loss in the isolated' perfused kidney. Biochem. Int. 20, 767778 . 
19. Milner, L. S., Wei, S. H., Stohs, S. J., Eldeen, Z. M. \& Houser, M. T. (1992) Role of glutathione metabolism in the reduction of proteinuria by dimethylthiourea in adriamycin nephrosis. Nephron 62, 192-197.

20. Guidi, G. C., Bellisola, G., Bonadonna, G., Manzato, F., Ruzzenente, O., Schiavon, R., Galassini, S., Liu, Q. X., Shao, H. R., Moschini, G., Perona, G. (1990) Selenium supplementation increases renal glomerular filtration rate. J. Trace Elem. Electrolytes Health Dis. 4, 157-161.

21. Degoulet, J. D., Legrain, M., Reach, 1., Aim, F., Deurirs, C., Rojas, P. \& Jacobs, C. (1982) Mortality risk factors in patients treated by chronic haemodialysis. Nephron 31, 103-110.

22. Torres, A. M., Rodriguez, J. V., Ochoa, J. E. \& Elias, M. M. (1986) Rat kidney function related to tissue glutatione levels. Biochem. Pharmacol. 35, 3355-3358.

23. Jung, K., Pergande, M., Graubaum, H-J., Fels, L. M., Endl, U. \& Stolte, H. (1993) Urinary proteins and enzymes as early indicators of renal dysfunction in chronic exposure to cadmium. Clin. Chem. 39, 757-765.

24. Fraser, C. \& Harris, E. (1989) Generation and application of data on biological variation in clinical chemistry. Crit. Rev. Clin. Lab. Sci. 27, 409-437.

25. Schentag, J. J., Sutfin, T. A., Plaut, M. E. \& Jusko, W. J. (1978) Early detection of aminoglycoside nephrotoxicity with urinary beta2-microglobulin. J. Med. 9, 201-210.

26. Schardijn, G. H. C. \& van Eps, L. W. S. (1987) $\beta_{2}$-Microglobulin: Its significance in the evaluation of renal function. Kidney Int. $32,635-641$.

Dr. Renzo Schiavon Laboratorio di Analisi Chimico Cliniche e Microbiologia Ospedale di Legnago via Gianella, 1 I-37045 Legnago (Verona) Italy 


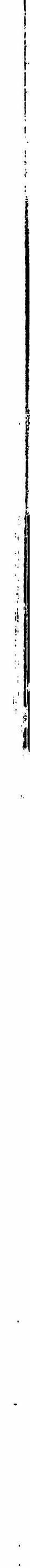

